Minoo Sharbafshaaer

O https://orcid.org/0000-0001-9887-5304

Zabihollah Hashemzahi²

(- https://orcid.org/0000-0001-7384-937X

Pravin Thomas ${ }^{3}$

Ohttps://orcid. org/0000-0002-3397-4667

Salman Keshtegart

(- https://orid.org/0000-0002-2076-6586

\section{Traumatic brain injury (TBI): exploring degrees and causes of TBI in mental health impairment by comprising gender differences}

\author{
Traumatismo cranioencefálico (TCE): explorando graus e causas do TCE \\ e comprometimento da saúde mental por compreender gênero
}

D0I: 10.1590/0047-2085000000292

\begin{abstract}
Objective: To exploring differences between degrees and causes of TBI in mental health impairment with comprising gender differences. Methods: The study was a cross-sectional observational study of TBI patients who bedded within 24 hours of presentation to the emergency department (ED), Khatam Hospital, located in Zahedan, Iran. Participants were randomized by a simple randomization technique. Information had been collected twice, first time screening patients by Glasgow Coma Scale score (GCS) and the second time was two months after discharging patients from the ED to estimate mental health impairment by using two separate clinical diagnostic tests. Results: The research considered 80 patients, with $66 \%$ being male and 34\% female. The median age for both genders estimated 23.5 years. There was a statistically significant difference between degrees and causes of TBI on the total score of hospital anxiety and depression. In particular, degree and cause of TBI with depression in males ( $M=$ $14.54, \mathrm{SD}=.22)$, and degrees of TBI on post-traumatic stress disorder in females $(M=87, S D=.7)$ were significant difference. Conclusion: The current investigation highlights the incidence of depression in male patients with severe levels of traumatic brain injury who injured by car accident multiple trauma; furthermore, this research found the remarkable rate of post-traumatic stress disorder in female patients with a mild degree of TBI. The researcher in traumatic brain injury should seriously deliberate and explore gender differences with the degree and cause of TBI in detail.
\end{abstract}

\section{KEYWORDS}

Traumatic brain injury, TBI, mental health, gender differences.

\section{RESUMO}

Objetivo: Explorar diferenças entre graus e causas de traumatismo cranioencefálico (TCE) no comprometimento de saúde mental de acordo com o gênero. Métodos: Estudo observacional transversal de pacientes com TCE que se hospitalizaram dentro de 24 horas após a apresentação no pronto-socorro (PS) no Hospital Khatam, localizado em Zahedan, Irã. Os participantes foram randomizados e as informações foram coletadas duas vezes: na primeira vez, na triagem, os pacientes foram avaliados pela Escala de Coma de Glasgow (GCS); na segunda vez, dois meses depois da alta do PS, eles foram avaliados para estimar o comprometimento da saúde mental usando dois instrumentos de avaliação independentes. Resultados: A amostra foi constituída de 80 pacientes, $66 \%$ sendo do sexo masculino e $34 \%$ do sexo feminino. A idade mediana para ambos os sexos estimada foi de 23,5 anos. Houve uma diferença estatisticamente significativa entre graus e causas de TCE no escore total de ansiedade hospitalar e depressão. Em particular, o grau e a causa de TCE estiveram associados com depressão no sexo masculino ( $M=14,54, \mathrm{DS}=0,22)$ e os graus de TCE, com transtorno de estresse pós-traumático em muIheres ( $M=87, D S=0,7)$. Conclusão: Este estudo destaca a incidência de depressão em pacientes do sexo masculino com níveis graves de lesão cerebral traumática e que se feriram por acidente de carro com trauma múltiplo; além disso, observamos uma notável taxa de transtorno de estresse pós-traumático em pacientes do sexo feminino com um grau leve de TCE. O pesquisador em lesão cerebral traumática deve explorar séria e detalhadamente as diferenças de gênero com o grau e a causa do TCE.

PALAVRAS-CHAVE

Lesão cerebral traumática, TCE, saúde mental, diferenças de gênero.

Received in: Apr/20/2020 Approved in: 0ct/18/2020

1 Young Researchers and Elite Club, Zahedan Branch, Islamic Azad University, Zahedan, Iran.

2 Department of Neurology, Zahedan University of Medical Sciences, Zahedan, Iran.

3 Department of Neurology, Queen Elizabeth Hospital Birmingham, University Hospitals Birmingham NHS Foundation Trust, Birmingham, United Kingdom.

4 Department of Medicine, Zahedan Branch, Islamic Azad University, Zahedan, Iran.

Address for correspondence: Minoo Sharbafshaaer. E-mail: minoshaaer@gmail.com 


\section{INTRODUCTION}

According to the World Health Organization, traumatic brain injury (TBI) is reported as the major cause of mortality and disability to the worldwide in the year 2020', with investing an enormous amount of economic ${ }^{2}$. In addition, TBI mainly caused by an external hit to the brain, accident or falling and move skull rather damage it, degrees of brain injury classified into mild, moderate, and severe. However, with that tumble in death and disability rates the proportions of people with complications, especially the neuro-behavioural effects of brain injury, has risen the mental health impairment.

In fact, degree and cause of TBI manifest various outcomes in mental health capacity especially vulnerability against anxiety, depression, post-traumatic stress disorder (PTSD) and physical structure in males and females. Meanwhile, mental health impairments described as disturbances in thinking, emotion, and/or behavior, these are a broad range of depression, anxiety, and PTSD ${ }^{3}$.

Furthermore, $\mathrm{TBI}$ results in short and long-term mental health syndromes in patients that associated with disabilities in neuropsychological or mental health impairment symptoms, including headache, depression, anxious behaviour, and memory impairments ${ }^{4}$. The common behavioural and neuropsychiatric conditions have seen following TBI reported; mood disorders, anxiety disorders and high risk of PTSD 5 .

Several studies have demonstrated risk for mental health disorder among individuals with TBI is markedly higher than in the general population also clear gender differences has been shown to the symptoms of mental health impairment, with degrees and causes of $\mathrm{TB}^{6}{ }^{6}$, because variety of factors regulates sex differences in $\mathrm{TB} \mid$, and it is believed that differences in mental health impairment after TBI can guide further clinical treatment?

At present, it is important to recognize degrees and causes of TBI in mental health disorder within males and females TBI patients ${ }^{8}$, besides, may mental health function have limited by the secondary effects of degrees and causes $\mathrm{TB}^{9}$ due to it shows complex neurologic and neuropathologic outcomes that always involved the patient's behavior ${ }^{10}$. Moreover, the temporal lobe obviously altered by changing mental health function after TBI ${ }^{11}$. Patients have a specific psychopathologic and severe neuropsychological pattern since braininjured individuals were in coping with the mental health impairment outcomes to promote their mental health ${ }^{12}$.

Mental health disorders condition in both genders could be explored by the degree and cause of the TBI. Emerging evidence reported that male and female nervous systems react differently to $T B I$. Several studies investigated TBI to emphasize the incidence of $\mathrm{TBI}$ on the male and female population. Although, only a few studies consider degrees and causes of $\mathrm{TBI}$ in mental health impairment within males/females. In the literature, degrees and causes of TBI have not been explored in great detail about mental health impairment considering in males and females. The present study exploring degrees and causes of TBI in mental health impairment within both genders also comparing various degrees and causes of TBI by gender differences. The study also set to identify any variable that differs between males and female population.

\section{METHODS}

\section{Participants and procedure}

This was a cross-sectional observational study of TBI patients aged between 18 and 66 years, who reported with TBI and they had sustained five major causes of traumatic brain injuries who bedded within 24 hours of presentation to the emergency department (ED), Khatam Hospital, located in Zahedan, Iran. Participants were randomized by a simple randomization technique. The study was developed from March 2017 to October 2017. Information had been collected twice, the first time was in the emergency trauma center: the Glasgow Coma Scale (GCS) according to medical records based on the ICD items has been used to assessing TBI's degree with the cause of TBI then the second time was two months after discharging patients from the ED, psychologist estimated mental health impairment through telephone. The evaluation tests were performed by two steps:

- Firstly, the GCS was used to assess degrees of TBI by the same neurologist. The patients were categorized into two groups (males/females);

- Secondary, two months after TBI injury, Hospital Anxiety and Depression Scale (HADS) and Posttraumatic Diagnostic Scale according to DSM-5 (PDS5) questionnaires measured mental health impairment by the expert psychologist and general practitioner.

Data concerning the degree of $\mathrm{TBI}$ contained three categories; severe, moderate, and mild, causes of the injury, involved; car accident (CA), car accident multiple trauma (CAMT), head trauma (HT), head trauma multiple trauma (HTMT), and falling.

We included TBI patients who were followed at an emergency department of a hospital, according to the following criteria: they should be 18 years old or older without any orthopaedic report. Furthermore, we excluded patients with a cerebrovascular accident, psychiatry disorder, central nervous system tumors, epilepsy, movement disorders, intellectual disability, pregnancy, and drug abusers.

\section{The demographic questionnaires}

The study according to the inclusion and exclusion criteria and their acceptance of the consent terms, then patients 
were enrolled prospectively after providing written informed consent and they answered two separate clinical diagnosis tests: HADS and PDS-5. The HADS questionnaire included the following tests: seven questions for anxiety and seven questions for depression. It takes 2-5 min to complete the questionnaire. Although anxiety and depression have been scored separately, the cut-off scores are available for quantification, for example, $8 \leq$ score for anxiety has a specificity of 0.9 sensitivity, as well as depression specificity 0.83 sensitivity ${ }^{13}$. The HADS is a welldesigned instrument for assessing emotional distress in the TBI population ${ }^{14}$. HADS viewed as a single scale of emotional distress to estimate stress symptoms separately for anxiety and depression in TBI patients with adequate reliability ${ }^{15}$.

PDS-5, is a self-report measure for PTSD, is based on the diagnostic criteria fifth edition of the Diagnostic and Statistical Manual of Mental Disorders. The receiveroperating-characteristic analysis yielded 28 cutoff scores to identify the possibility of PTSD. The PDS-5 is a valid and reliable measure of DSM-5 PTSD symptomatology ${ }^{16}$. Foremost demographic data for this investigation were recorded age, gender, GCS score, causes and levels of TBI then gathered two questionnaires from each TBI cases.

\section{Statistical analysis}

Data were analyzed using SPSS.25 software. Statistical analyses were performed using Multivariate ANOVA (MANOVA) for comparison of the mental health impairment among degrees and causes of TBI as a fixed factor and gender group to identify potential covariates associated with mental health impairment. Normally distributed variables were presented as the means and standard deviations, also post-hoc test Bonferroni correction checked for gender group, while all statistical tests were done to conclude any significant difference at $5 \%$ level.

\section{Ethical aspects}

Approval research was done by the Zahedan University of Medical Sciences with a declaration of Head's Khatam Hospital (Trauma Centre) in Zahedan based on these considerations and research ethics. Participants answer questions confidently, whereas they ensured that their information keeps secure.

\section{RESULTS}

The research estimated 80 patients by G-power software with 95 per cent interval confidence, 66\% TBI patients being male, and 34\% female. The median age for both genders estimated 32.23 years and standard deviation of 12.51. (range 18-66 years) The mean GCS score TBI patients was 10.4 (SD = 3.2). The following degrees of TBI descriptive data reported, $10 \%$ severe, $50 \%$ moderate, and $40 \%$ for mild TBI.

Concerning causes of $\mathrm{TBI}$ data recorded when the patients presented to the ED: CA, 26\%; CAMT, 38\%; HT, 24\%; HTMT, 2\%; and fall, 10\%.

One-way between-groups multivariate analysis of variance was conducted to exploring degrees and causes of TBI in mental health impairment within males/females. Three dependent variables were counted: hospital anxiety $(\mathrm{HA})$, hospital depression (HD), and PTSD. The independent variables were the degree and cause of TBI. Normality linearity univariate and multivariate outlier homogeneity of variance-covariance matrices and multicollinearity, with no serious violations, noted.

Evaluating the hospital anxiety and depression for the degree and cause of TBI, we observed that the degrees of TBI showed a higher level of injury and major cause of TBI gross total score of the hospital anxiety and depression extremely hospital depression, by contrast, hospital anxiety presented no significant difference on the degree and cause of injury. One-way between-groups multivariate analysis of variance indicated statistically significant difference between degrees $F(4,19)=4.7, p=.021$; Wilks' Lambda $=.7$; partial eta squared $=.32$; observed power $=.74$; Bonferroni alpha level $=01$ and causes of TBI $F(4,20)=3.3, p=.032 ;$ Wilks' Lambda $=.83$; partial eta squared $=.4$; observed power $=.737$; Bonferroni alpha level $=014$ integrated with total score of hospital anxiety and depression, whereas no significant association between degree $F(3,39)=1.57, p=.24$ and cause of TBI $F(3$, $39)=1.58, p=.21$ with hospital anxiety (Table 1).

We detected that the degrees and causes of TBI overweight hospital depression notably in males TBI patients. Meanwhile, multivariate analysis of variance test shows there was statistically significant difference between degrees $F(3,39)=7.02, p=.005 ; W_{i l k s}$ Lambda $=.81 ;$ partial eta squared

Table 1. Significance levels between degrees and causes of TBI in mental health impairment score

\begin{tabular}{lcccc}
\hline \multirow{2}{*}{ Mental health score } & \multicolumn{2}{c}{ Degree } & \multicolumn{2}{c}{ Cause } \\
\cline { 2 - 5 } & $\mathbf{F}$ & $\mathbf{p}$ & $\mathbf{F}$ & $\mathbf{p}$ \\
\hline Hospital Anxiety and Depression & 4.7 & $.021^{*}$ & 3.3 & $.032^{*}$ \\
Hospital Anxiety & 1.57 & .24 & .58 & .21 \\
Hospital Depression & 7.02 & $.005^{* *}$ & 3.01 & $.041^{*}$ \\
Post-Traumatic Stress Disorder & 5.84 & $.002^{* *}$ & .38 & .82 \\
\hline
\end{tabular}

$p$-value: $F$ Multivariate ANOVA test. ${ }^{*}$ Significant differences at $(p<0,01) .{ }^{* *}$ Significant differences at $(p<0,001)$. 
$=.412$; observed power $=.884$; Bonferroni alpha level $=008$ and causes of TBI on the integrated hospital depression, $F$ (3, $39)=3.01, p=.041$; Wilks' Lambda $=.81$; partial eta squared $=.19$; observed power $=.665$ (Table 1). When the result for the dependent variables were assessed distinctly the only differences to reach statistical significance using Bonferroni adjusted alpha level of .013, was hospital depression, F (3, $39)=3.88, p=.016$; partial eta squared $=.22$. An inspection of the mean scores demonstrated that males stated slightly higher levels of hospital depression $(M=14.54$, SD $=.22)$ than females ( $M=13.57, S D=.28$ ) (Table 2). Moreover, males inferred statistically difference rate of depression in sever level of TBI (Figure 1) and CAMT injury (Figure 2).

We observed that there was statistically significant difference between degrees of TBI on the combined PTSD, F $(3,43)=5.841, p=.002 ;$ Wilks' Lambda $=.71$; partial eta squared $=.3$; observed power $=.934$ (Table 1). When the result for the dependent variables were considered separately the only differences to reach statistical significance using Bonferroni adjusted alpha level of .006, was PTSD, $F(1,45)=4.73, p=$ .035; partial eta squared $=.1$. An inspection of the mean scores indicated that females reported fairly higher levels of $\operatorname{PTSD}(M=87, S D=.7)$ than males $(M=85.53, S D=.55)$ (Table 2) also, females shows more difference PTSD in mild degree of TBI (Figure 3).

Table 2. The means of mental health impairment subgroups scores of both genders

\begin{tabular}{lcc}
\hline \multirow{2}{*}{ Mental health subgroups } & Males & Females \\
\cline { 2 - 3 } & $\mathbf{X} \pm \mathbf{S D}$ & $\mathbf{X} \pm \mathbf{S D}$ \\
\hline Hospital Anxiety and Depression & $29.84 \pm 2.52$ & $28.09 \pm 1.92$ \\
Hospital Anxiety & $14.84 \pm 1.53$ & $14.27 \pm 1.1$ \\
Hospital Depression & $14.54 \pm .22$ & $13.57 \pm .28$ \\
Post-Traumatic Stress Disorder & $85.53 \pm .55$ & $87 \pm .7$ \\
\hline
\end{tabular}

$\mathrm{X}$ : mean; SD: standard deviation. Scores ranged for each domain.

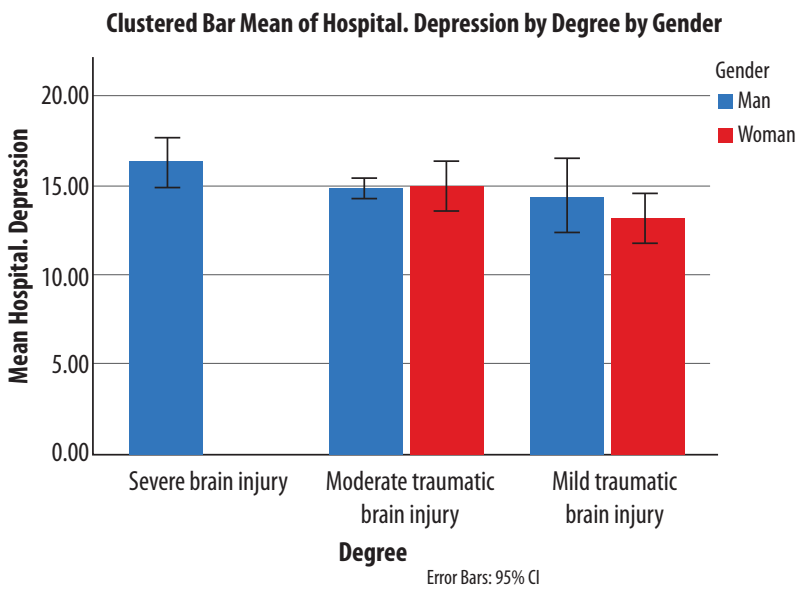

Figure 1. Prevalence of hospital depression with degrees of traumatic brain injury in males and females.

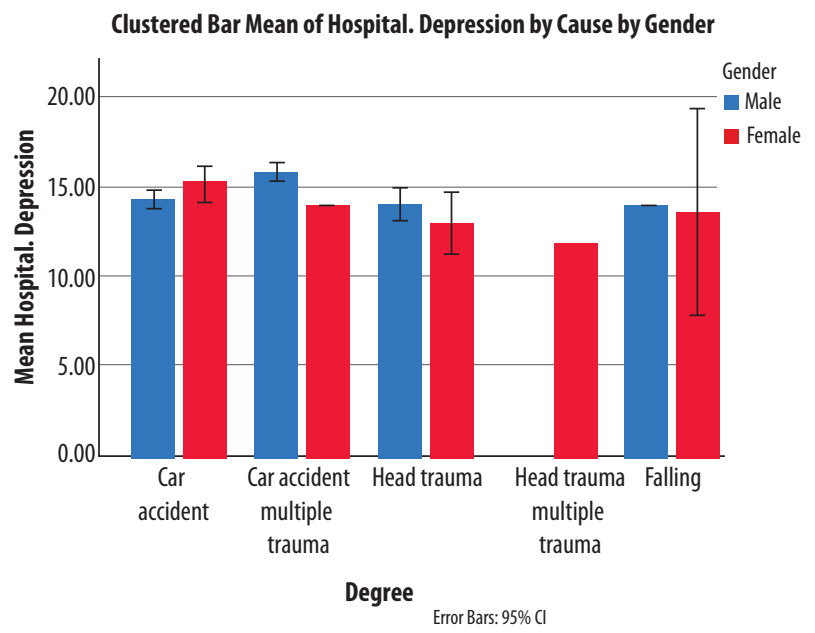

Figure 2. Various incidence of hospital depression with causes of TBI in both genders.

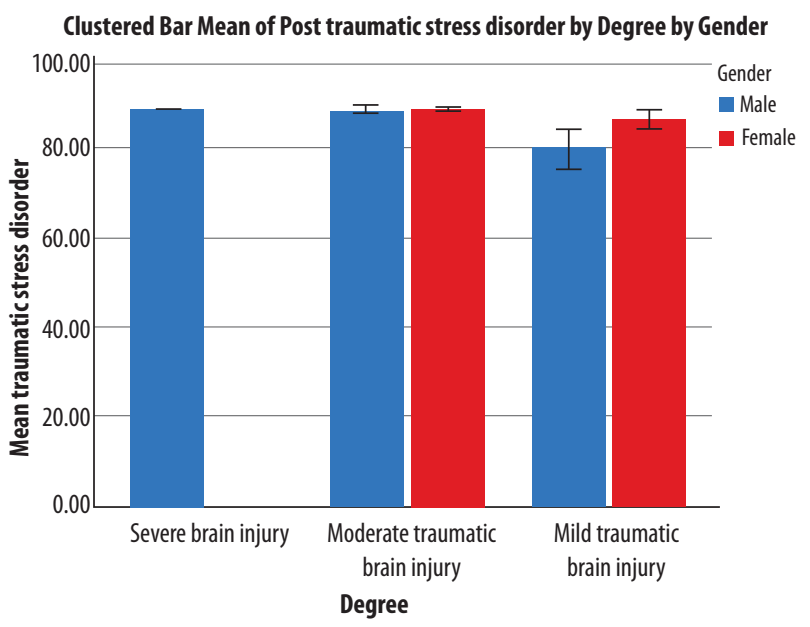

Figure 3. Differences between post-traumatic stress disorder with degree of traumatic brain injury within males and females.

\section{DISCUSSION}

The current study examines mental health impairment subsequently as an effort to highlight to give more attention toward degrees and causes of TBI in mental health outcomes in males and females. TBI patients suffer from various mental health impairment ${ }^{17}$ with a high risk of developing psychopathologic disorders ${ }^{18}$. The present research was intended to understand the contribution of degree and cause of TBI in mental health impairment (anxiety, depression, and PTSD) and demographic characteristics, within both genders.

Degree and cause of TBI integrated with a total score of hospital anxiety and depression in male and female, especially degree and cause of TBI related to depression in male patients, while the level of TBI associated with PTSD in females. In other words, the degrees and causes of TBI in mental health outcomes within females and males TBI 
injured that was drafted precisely for research purposes (the estimating were not done for medical treatment purposes) on a prospective basis in a hospital setting were considered.

Incidence of TBI in males and females shows various degrees of TBI that affected their mental health impairment through gender biology. This research declared male patients at the sever level of TBI by CAMT suffer from depression more than female patients, also other findings indicate that males with TBI are at a higher risk for depression than females ${ }^{19,20}$, hence women reported better mental consequences than men after $\mathrm{TB}^{21}$. Although Iranian men with strong physically have less resistance against depression than women ${ }^{22}$ then, for this reason, males consume more alcohol and drugs to fight depression instead of talk and report their depression mood so men who diagnosed with depression are fewer than women ${ }^{23}$.

According to the male sever level of TBI who experiencing depression, other researchers indicated depression impairment related to a higher degree of $\mathrm{TB}^{24}$, approximately severe level of TBI should routinely screen by health providers to set initiate treatment for depression after $\mathrm{TB}^{25}$. In the following the current study findings, CAMT associated with depression. further studies have reported CA patients underwent from depression ${ }^{26}$; and, HT patients described psychiatric impairment ${ }^{27}$. Whereas recently research admitted depression was common psychiatric complications for all-degree and cause of TB| ${ }^{28}$. Moreover, they need to put caregivers at risk for depression ${ }^{29}$.

The present research found the female patients, particularly with mild TBI, experienced more PTSD incidence than male, indeed it's depending on female's personality characteristics $^{30}$. In the total population of TBI patients, there is also a twofold increased expression of PTSD in women compared to men ${ }^{10}$ and in Iran PTSD is more common in women after TBI, so women have almost twice as many symptoms ${ }^{31}$. Meanwhile, the female population had a greater number of deaths and disabilities than males ${ }^{32}$. Against our research other investigations declared females and males in PTSD found the same incidence ${ }^{33}$. This research argued mild degrees of TBI was associated with PTSD. According to the present research findings studies declared that PTSD was observed in mild TBI and developing risk of PTSD $^{34}$, and mild TBI patients indicate longer-term PTSD ${ }^{35}$. But other investigation confirmed, severe degree of TBI was related to PTSD; severe TBI demonstrated the remarkable impairments $^{36}$. At that point, TBI significantly predicted PTSD at 6 months after injury ${ }^{37}$. Besides the study shows PTSD was the common diagnosis in all three degrees of $\mathrm{TB}^{38}$, so rehabilitation after TBI may be enhanced by the management of PTSD ${ }^{39}$.

Gender differences play an important role in $\mathrm{TB}^{40}$ to diagnosis mental health impairment by including degrees and causes of TBI (anxiety, depression, and PTSD), this investigation evaluated severe male TBI patients suffer from the depression while mild female TBI patients reported PTSD. Maybe it's as common as major mental health impairment after $\mathrm{TB}^{41}{ }^{11}$, owing to mental health disorders associated with disruption of cortical-subcortical circuits ${ }^{42}$. In general, each degree and causes of injury can lead to a distinct clinical condition that requires careful assessment and appropriate management to reduce long-term disability ${ }^{43}$.

\section{CONCLUSIONS}

The current investigation highlights the incidence of depression in male patients with severe levels of TBI who injured by CAMT; furthermore, this research found the remarkable rate of PTSD in female patients with a mild degree of TBI. Further studies are necessary to be done to ensure the TBI researcher should seriously deliberate mental health impairment and explore gender difference with degree and cause of TBI in detail.

\section{INDIVIDUAL CONTRIBUTIONS}

All collaborators meet all the following conditions: (1) had substantially contributed to conception and design or analysis and interpretation of data; (2) had substantially contributed to drafting the article or revising it critically for important intellectual content; and (3) had given the final approval of the version to be published.

\section{CONFLICT OF INTERESTS}

The authors declare no conflict of interest.

\section{ACKNOWLEDGEMENTS}

Thanks are due to those who provided expert clinical reports during the preparation of this review and to members of the Khatam Hospital Emergency Department in Zahedan city.

\section{REFERENCES}

1. Mistry J, Murray N. Traumatic brain injury in adults. InnovAiT. 2017;10(10):608-13.

2. Johnson WD, Dylan P Griswold DP. Traumatic brain injury: a global challenge. Lancet Neurol. 2017;16(12):949-50.

3. National Collaborating Centre for Mental Health. Common Mental Health Disorders: Identification and Pathways to Care. Leicester (UK): British Psychological Society; 2011. NICE Clinical Guidelines, №. 123. 
4. Mckee AC, Daneshvar DH. The neuropathology of traumatic brain injury. Handb Clin Neurol. 2015;127:45-66

5. Osborn AJ, Mathias JL, Fairweather-Schmidt AK, Anstey KJ. Anxiety and comorbid depression following traumatic brain injury in a community-based sample of young, middle-aged and older adults. J Affect Disord. 2017;15;213:214-21.

6. Lavoie S, Sechrist S, Quach N, Ehsanian R, Duong T, Gotlib IH, et al. Depression in Men and Women One Year Following Traumatic Brain Injury (TBI): A TBI Model Systems Study. Front Psychol. 2017;8:634.

7. Ma C, Wu X, Shen X, Yang Y, Chen Z, Sun X, et al. Sex differences in traumatic brain injury: a multi-dimensional exploration in genes, hormones, cells, individuals, and society. Chin Neurosurg J. 2019:5:24.

8. Obenaus A. Traumatic Brain Injury. Reference Module in Neuroscience and Biobehavioral Psychology. 2016;329-40.

9. Singh K, Kothare SV. Traumatic Brain Injury. In: Kothare S, Quattrucci Scott R (eds.). Sleep Disorders in Adolescents. Cham: Springer; 2017.p. 187-201.

10. Schönberger M, Ponsford J, Gould KR, Johnston L. The temporal relationship between depression, anxiety, and functional status after traumatic brain injury: a cross-lagged analysis. J Int Neuropsychol Soc. 2011;17(5):781-7.

11. Wiseman TA, Curtis K, Lam M, Foster K. Incidence of depression, anxiety and stress following traumatic injury: a longitudinal study. Scand J Trauma Resusc Emerg Med. 2015;23:29.

12. Mauri MC, PalettaS, Colasanti A, Miserocchi G, Altamura AC. Clinical and neuropsychological correlates of major depression following post-traumatic brain injury, a prospective study. Asian J Psychiatr. 2014;12:118-24.

13. Stern AF. The Hospital Anxiety and Depression Scale. Occup Med (Lond). 2014;64(5):393-4.

14. Schönberger M, Ponsford J. The factor structure of the Hospital Anxiety and Depression Scale in individuals with traumatic brain injury. Psychiatry Res. 2010;179(3):342-9.

15. Skilbeck C, Holm K, Slatyer M, Thomas MD, Bell T. The Factor Structure of the Hospital Anxiety and Depression Scale (HADS) in a Traumatic Brain Injury (TBI) Population. Brain Impairment. 2012;12(1):22-32.

16. Foa EB, McLean CP, Zang Y, Zhong J, Powers MB, Kauffman BY, et al. Psychometric properties of the Posttraumatic Diagnostic Scale for DSM-5 (PDS-5). Psychol Assess. 2016;28(10):1166-71.

17. Ahmed S, Venigalla H, Madhuri Mekala H, Sara Dar, Mudasar H, Shahana A. Traumatic Brain Injury and Neuropsychiatric Complications. Indian J Psychol Med. 2017;39(2):114-21.

18. Glaesser J, Neuner F, Lütgehetmann R, Schmidt R, Elbert T. Posttraumatic Stress Disorder in patients with traumatic brain injury. BMC Psychiatry. 2004;4:5.

19. Sigurdardottir S, Andelic N, Roe C, Schanke AK. Depressive symptoms and psychological distress during the first five years after traumatic brain injury: relationship with psychosocial stressors, fatigue and pain. J Rehabil Med. 2013;45:808-14.

20. Albrecht JS, Kiptanui Z, Tsang Y, Khokhar B, Liu X, Simoni-Wastila L, et al. Depression among older adults after traumatic brain injury: a national analysis. Am. J. Geriatr. Psychiatry. 2015;23:607-14.

21. Farace $E$, Alves WM. Do women fare worse: a metaanalysis of gender differences in traumatic brain injury outcome. J Neurosurg. 2000;93(4):539-45.

22. Young Journalists Club. Depression, silent and dangerous disease for Iranian men. 2018. Available from: https://www.yjc.ir/fa/news/6133665/. Accessed in: May 20, 2020.

23. Royal College of Psychiatrists. Men and depression. 2011. Available from: https://www. rcpsych.ac.uk/mental-health. Accessed in: May 20, 2020.
24. Gomez R, Skilbeck C, Thomas M, Slatyer M. Growth Mixture Modeling of Depression Symptoms Following Traumatic Brain Injury. Front Psychol. 2017;8:1320.

25. Silverberg ND, Panenka WJ. Antidepressants for depression after concussion and traumatic brain injury are still best practice. BMC Psychiatry. 2019;19(1):100.

26. Kuch K, Swinson RP, Kirby M. Post-traumatic stress disorder after car accidents. Can J Psychiatry. 1985;30(6):426-7.

27. O'Shanick GJ, Scott R, Peterson LG. Psychiatric referral after head trauma. Psychiatr Med. 1984;2(2):131-7.

28. Leong Bin Abdullah MFI, Ng YP, Sidi HB. Depression and anxiety among traumatic brain injury patients in Malaysia. Asian J Psychiatry. 2018;37:67-70.

29. Ennis N, Rosenbloom BN, Canzian S, Topolovec-Vranic J. Depression and anxiety in parent versus spouse caregivers of adult patients with traumatic brain injury: a systematic review. Neuropsychol Rehabil. 2013;23(1):1-18.

30. Hoffman JM, Dikmen S, Temkin N, Bell KR. Development of posttraumatic stress disorder after mild traumatic brain injury. Arch Phys Med Rehabil. 2012;93(2):287-92.

31. Khodadadi N, Ghanbari Khanghah A, Mousavi SM, Khaleghdoost T, Moosavi MJ. Related factors to onset of post-traumatic stress disorder after road accidents. J Holist Nurs Midwifery. 2013;24(72):9-17.

32. Munivenkatappa A, Agrawal A, Shukla DP, Kumaraswamy D, Devi BI. Traumatic brain injury: Does gender influence outcomes? Int J Crit IIIn Inj Sci. 2016;6(2):70-3.

33. Horn G, Lewis F, Russell R, Kemp D. Anxiety following traumatic brain injury: Impact on post hospital rehabilitation outcomes. Phys Med Rehabil Res. 2017;2.

34. Choi MS, Seo SJ, Oh CH, Kim SH, Cho JM. Incidence of Post-Traumatic Stress Disorder after a Mild Traumatic Brain Injury: Preliminary Investigation Using the Brief Neuropsychological Screening Test. J Korean Neurosurg Soc. 2014;55(4):190-4.

35. Haarbauer-Krupa J, Taylor CA, Yue JK, Winkler EA, Pirracchio R, Cooper SR, et al. Screening for Post-Traumatic Stress Disorder in a Civilian Emergency Department Population with Traumatic Brain Injury. J Neurotrauma. 2017;34(1):50-8.

36. Liebert MA; Inc./Genetic Engineering News. CDC study identifies patients with mild traumatic brain injury at increased risk of PTSD. J Neurotrauma. 2016.

37. Joseph S, Masterson J. Posttraumatic Stress Disorder and Traumatic Brain Injury: Are They Mutually Exclusive? J Trauma Stress. 1999;12(3):437-53.

38. Bryant RA, Marosszeky JE, Crooks J, Baguley IJ, Gurka JA. Posttraumatic stress disorder and psychosocial functioning after severe traumatic brain injury. J Nerv Ment Dis. 2001;189(2):109-13.

39. Warren AM, Boals A, Elliott TR, Reynolds M, Weddle RJ, Holtz P, et al. Mild traumatic brain injury increases risk for the development of posttraumatic stress disorder. J Trauma Acute Care Surg. 2015;79(6):1062-6.

40. Wright DW, Espinoza TR, Merck LH, Ratcliff JJ, Backster A, Stein DG. Gender differences in neurological emergencies part II: a consensus summary and research agenda on traumatic brain injury. Acad Emerg Med. 2014;21(12):1414-20.

41. Hart T, Brenner L, Clark AN, Bogner JA, Novack TA, Chervoneva I, et al. Major and minor depression after traumatic brain injury. Arch Phys Med Rehabil. 2011;92(8):1211-9.

42. Isaac L, Main KL, Soman S, Gotlib IH, Furst AJ, Kinoshita LM, et al. The impact of depression on Veterans with PTSD and traumatic brain injury: a diffusion tensor imaging study. Biol Psychol. 2015;105:20-8.

43. Jagnoor J, Cameron ID. Traumatic brain injury - support for injured people and their carers. Aust Fam Physician. 2014;43(11):758-63. 